\title{
Causes of Absenteeism Rate among Staff Nurses at Medina Maternity and Child Hospital
}

\author{
FL. Alharbi ${ }^{{ }^{*}}$, TB. Almuzini ${ }^{2}$, AA. Aljohani ${ }^{2}$, KA. Aljohani ${ }^{2}$, AR. Albowini ${ }^{3}$, \\ ME. Aljohani ${ }^{4}$, MM. Althubyni ${ }^{5}$ \\ Departments of Nursing and Pharmacy \\ 1-Alsafiah Health Care, Medina, 2- King Fahd Hospital, Medina,3- Maternity and Child Hospital, \\ Medina, 4- Primary Health Care, Medina, 5- AL Madinah Specialist hospital, Medina, SA \\ *Corresponding author: FL. Alharbi, Mobile No.+966594263278, E-Mail: Fahdiah1331@ gmail.com
}

\begin{abstract}
Background: Multiple factors are associated with absenteeism among nursing staff around the world with an increasing rate that affects the delivery of health care to patients and reflects non-satisfaction of the nursing staff. Objectives: Evaluating the factors associated with high rates of absenteeism among staff nurse in Medina Maternity and Child Hospital (MMCH).

Methods: This is a descriptive study that was conducted among a sample of 405 nurses working at MMCH. The study tool included a questionnaire sheet of 2 parts as demographics and causes of absenteeism. All the nurses were interviewed and asked to fill up the questionnaire sheet.

Results: Most of the included nurses had Diploma degree and about 5 years of experience $(50.4 \%)$.

The majority of nurses had good knowledge about the effects of absenteeism on work performance. The most common etiological factors associated with absenteeism were no overtime payment (75.6\%) and social reasons among $77.8 \%$ of nurses.

Conclusion: The increasing rates of absenteeism among nursing staff working in $\mathrm{MMCH}$ were not founding the payment for overtime work followed by social reasons for nurses. Thus, considering over-time and working status as shift times and numbers of nurses per shift are important motivators that could decrease the rates of absenteeism among nursing staff and increase the rates of nurses satisfaction to their jobs.
\end{abstract}

Keywords: Staff Nurses, Absenteeism, Rates, Medina, KSA.

\section{INTRODUCTION}

Absenteeism has many definitions including missing a day or many days of the work. Another definition could be unplanned absence without excuse or warning ${ }^{(\mathbf{1}, \mathbf{2})}$. It is a worldwide problem with an exaggerated rates which could result in hindering the delivery of health care to patients that associated with shortage of number of available health staff ${ }^{(3)}$. The absenteeism of employee is Employee absenteeism which is a remarkable issue that was found to affect the productivity of all work sectors all over the world (4). Many studies have been conducted to assess the absence among health stuff members especially among nurses which was the focus of researchers showing that sickness is the most prevalent cause for absence ${ }^{(\mathbf{1})}$ as well as job satisfactions and turn overs ${ }^{(5)}$.The absence of nurses is significantly associated with burden of health care settings which impose many costs for health organizations ${ }^{(6)}$.

Also, it could result in increasing the work load on other nurses as well as comprising the patients' health outcomes thus increase the mortality rates ${ }^{(7,8)}$.

The overload in work was a result of absenteeism among nurses that could decrease the motivation of the work. Nurses are often overloaded when covering the absence of their absent colleagues, which might decrease their job motivation and productivity and could differ from one setting to another one in the same hospital ${ }^{(1,}$ 9). This study examines the causes of absenteeism among hospital nurses in Madinah, Saudi Arabia.

\section{METHODS \\ Study Design}

A descriptive cross sectional study that was conducted at medina maternity and child hospital, Kingdom of Saudi Arabia (KSA). Study Population:

A random sample of 405 nurses were included in the study from different departments from both genders. All the nurses were interviewed and asked to fill up a questionnaire sheet to assess the causes of absenteeism.

\section{Study tools}

The study tool was a structure interview sheet that included two parts. The first part included questions related to the demographics of the nurses including age, sex, education and marital status. The second part of the sheet included a questionnaire to assess the causes of absence. The questionnaire was approved by the supervisors after reviewing the available literature and studies 
associated with the causes of absence among nurses then validated and translated into simple Arabic.

\section{Ethical Considerations}

Ethical approval was obtained from the ethical committee for human research and faculty of Nursing, Taibah University. All the included nurses gave a consent approval for participating in the present study.

\section{Statistical analysis}

The data were fed up into windows and analyzed using SPSS V. 20. The data were shown as distributions and percentages.

\section{RESULTS}

\section{- Demographics of the included subjects}

Table (1) showed that the age of included nurses was less than 20 years old among $4 \%$ of them, from 20-30 years among $68.3 \%$ of them and $27.7 \%$ were older than 30 years. Most of the nurses were females $(98.5 \%)$ and $76 \%$ were holding Diploma degree, while $23.5 \%$ were graduated and only $0.5 \%$ of them within different level of education. The nurse's experience was from $2-5$ years among $50.4 \%$ of them and from 6 months to 1 year among $39 \%$.

Table (1): Demographics of Included nurses

\begin{tabular}{|l|c|c|}
\hline Age (Year) & No. & $\begin{array}{l}\text { Percentage } \\
(\mathbf{\%})\end{array}$ \\
\hline Less than 20 years & $\mathbf{1 6}$ & $\mathbf{4}$ \\
\hline 20-30 years & $\mathbf{2 7 7}$ & $\mathbf{6 8 . 3}$ \\
\hline More than 30 years & $\mathbf{1 1 2}$ & $\mathbf{2 7 . 7}$ \\
\hline Gender & & \\
\hline Female & 49 & 98.5 \\
\hline Male & 6 & 1.5 \\
\hline Level of education & 308 & \\
\hline Diploma & 95 & 23.5 \\
\hline Bachelor degree & 2 & 0.5 \\
\hline Other & & \\
\hline Nurses' experience & 43 & 10.6 \\
\hline$<$ months & 158 & 39 \\
\hline 6 months- 1 year & 204 & 50.4 \\
\hline 2-5 years & & \\
\hline
\end{tabular}

\section{- Distribution of the studied samples regarding their daily work practices}

Table (2) showed the distribution of the nurses regarding daily work practices as the majority of nurses may take leave more than 5 days per month (43.5\%), $87.2 \%$ attend daily on duty time, $71.9 \%$ thought that absenteeism could delay the work performance, $75.3 \%$ help in the work of an employee, $49.4 \%$ thought that the working environment was fair, $67.4 \%$ thought that there is a work pressure in their department and $50.6 \%$ face strict supervision as a pressure from their organization. The nurses thought that good employee relation $(27.8 \%)$, recognition of the work $(27.7 \%)$, Incentive and bonus based on perform $(27.7 \%)$ and finally work environment $(16.8 \%)$ could decrease the rates of absenteeism. 
Table (2): Distribution of the studied samples regarding their daily work practices

\begin{tabular}{|c|c|c|}
\hline Duration of the leave taken by nurse in a month & Frequency & Percent \\
\hline 1 day & 92 & $22.7 \%$ \\
\hline 2-3 days & 108 & $26.7 \%$ \\
\hline 4-5 days & 29 & $7.1 \%$ \\
\hline More than 5 days & 176 & $43.5 \%$ \\
\hline \multicolumn{3}{|c|}{ Is the nurse attending the daily duty on time? } \\
\hline Yes & 353 & $87.2 \%$ \\
\hline No & 52 & $12.8 \%$ \\
\hline \multicolumn{3}{|c|}{ Nurse opinion about the effect of absenteeism } \\
\hline Cause work stress & 114 & $28.1 \%$ \\
\hline Delayed work performance & 291 & 71.9 \\
\hline \multicolumn{3}{|c|}{ Nurses satisfaction level about your performance } \\
\hline Highly satisfied & 123 & $30.4 \%$ \\
\hline Neutral & 250 & $61.7 \%$ \\
\hline Dissatisfied & 24 & $5.9 \%$ \\
\hline Highly dissatisfied & 8 & $2 \%$ \\
\hline \multicolumn{3}{|c|}{ Are the nurses helping in the work of an employee } \\
\hline Yes & 305 & $75.3 \%$ \\
\hline No & 100 & $24.7 \%$ \\
\hline \multicolumn{3}{|c|}{ Nurse opinion regarding work environment } \\
\hline poor & 27 & $6.7 \%$ \\
\hline fair & 200 & $49.4 \%$ \\
\hline good & 101 & $24.9 \%$ \\
\hline excellent & 77 & $19 \%$ \\
\hline \multicolumn{3}{|c|}{ The nurses thought regarding the work pressure on the job } \\
\hline No, there is no work pressure & 132 & $32.6 \%$ \\
\hline Yes, There is a lot of work pressure & 273 & $67.4 \%$ \\
\hline \multicolumn{3}{|c|}{ Type of work pressure the nurse facing in the organization } \\
\hline Improper environment & 200 & $49.4 \%$ \\
\hline Strict supervision & 205 & $50.6 \%$ \\
\hline \multicolumn{3}{|c|}{ Nurses opinion about the factors to reduce the absenteeism } \\
\hline Good employee relation & 113 & $27.8 \%$ \\
\hline Work environment & 68 & $16.8 \%$ \\
\hline Recognition of the work & 112 & $27.7 \%$ \\
\hline Incentive and bonus based on perform & 112 & $27.7 \%$ \\
\hline
\end{tabular}

- Nurse's beliefs regarding the causes of absenteeism:

The most common causes of absenteeism among the included nurses were shortage of staff $(59 \%)$, increased work load in the unit $(71.9 \%)$, no overtime payment $(75.6 \%)$, easy access of sick leaves $(50.1 \%)$, social reasons $(77.8 \%)$, no action taken for repeated absence $(77.1 \%)$, lack of motivation (65.4\%), lack of responsibility (58\%), low knowledge and practical skills about certain procedures $(64.2 \%)$, difficult of transportation (68.4\%) and difficulty to take permission during the shift $(74.8 \%)$. However, the least common causes were inability to understand or implant the sick leave policy and ignorance about hospital rules and practice $(46.4 \%)$. 
Table (3): Nurse's beliefs regarding the causes of absenteeism

\begin{tabular}{|l|c|c|}
\hline & Yes & No \\
\hline Shortage of staff & $239(59 \%)$ & $166(41 \%)$ \\
\hline Increase workload in the unit & $291(71.9 \%)$ & $114(28.1 \%)$ \\
\hline No overtime payment & $316(75.6 \%)$ & $89(24.4 \%)$ \\
\hline Easy access of sick leave & $203(50.1 \%)$ & $202(49.9 \%)$ \\
\hline Social reasons & $315(77.8 \%)$ & $90(22.2 \%)$ \\
\hline NO action taken for repeated absences & $288(71.1 \%)$ & $117(28.9 \%)$ \\
\hline Sick leave policy is not strictly understood and implemented & $178(44 \%)$ & $227(56 \%)$ \\
\hline Lack of motivation of the staff & $265(65.4 \%)$ & $140(34.6 \%)$ \\
\hline Lack of responsibility & $235(58 \%)$ & $170(42 \%)$ \\
\hline Lack of knowledge and practical skills about certain procedures & $260(64.2 \%)$ & $145(35.8 \%)$ \\
\hline Difficult of transportation & $277(68.4 \%)$ & $128(31.6 \%)$ \\
\hline Ignorance about hospital rules and practice & $188(46.4 \%)$ & $217(53.6 \%)$ \\
\hline Difficult to take permission during the shift & $303(74.8 \%)$ & $102(25.2 \%)$ \\
\hline
\end{tabular}

\section{DISCUSSION}

Recent studies showed that absenteeism alone wouldn't lower the quality of the health care for patients unless is associated with high patient load with high nurse absenteeism ${ }^{(7,8,10)}$.

The present study showed that the absence among nursing stuff was attributed to social reasons in (77.8\%), no overtime payment (75.6\%), difficult to take permission during the shift, increase in the work load in the unit (71.9\%) and no action taken for repeated absences $(71.1 \%)$.

In the same respect, the social reasons and family matters were the most common causes of nurses absence in KSA and in South Africa ${ }^{(\mathbf{1 1}, \mathbf{1 2})}$.

Remarkably, the factors related to work and organization policies as well as restrictions of overtime payment were found to be significantly affecting the rates of absenteeism including work load, no overtime payment and difficulty to take permission for absence. These results were in agreement with those results showing that increase the rates of absenteeism among nurses $(13,14)$

Work load and other stressors form organizations are also predictors of absenteeism and dissatisfaction among the stuff members ${ }^{(15)}$. Also, ineffective routine, work pressure, inability to manage the working tasks as well as uncomfortable environment have a major influence on the rates of absence ${ }^{(9,16)}$.

The present study has some limitations including that the rates of absenteeism per month were reported by the nurses themselves and not from recorded files. The data about their daily practices were also provided by the nurses themselves and could be interrupted because they

may want to show themselves as efficient nurses. The third limitation is that the study should include the health regulation and absenteeism policy of the hospital.

This study has also some strength factors as it presented the point of view of the nurses toward the causes of absenteeism and the proper way to solve this problem as taking overtime for extra work and managing the work status as well as implanting good employee relationship.

\section{CONCLUSION}

The increasing rates of absenteeism among nursing staff working in $\mathrm{MMCH}$ were because of not founding the payment for overtime work followed by social reasons for nurses. Thus, considering over-time and working status as shift times and numbers of nurses per shift are important motivators that could decrease the rates of absenteeism among nursing staff and increase the rates of nurses satisfaction to their jobs.

\section{REFERENCES}

1. Sancinetti TR, Soares AV, Lima AF, Santos NC, Melleiro MM, Fugulin FM et al. (2011): [Nursing staff absenteeism rates as a personnel management indicator]. Revista da Escola de Enfermagem da U S P., 45:1007-1012.

2. Martinato MC, Severo DF, Marchand EA, de Siqueira HC (2010): [Absenteeism in nursing staff an integrative review]. Revista gaucha de enfermagem, 31:160-166.

3. Kurcgant P, Passos AR, Oliveira JM, Pereira IM, Costa TF (2015): Absenteeism of nursing staff: 
decisions and actions of nurse managers. Rev Esc Enferm USP., 49:35-41.

4. van den Oetelaar WF, van Stel HF, van Rhenen W, Stellato RK,Grolman W (2016): Balancing nurses' workload in hospital wards: study protocol of developing a method to manage workload. BMJ Open, 6:e012148.

5. vJAFAR JE, Hajibabaee F, Farahaninia M, Joolaee S, Hosseini F (2014): Relationship between job satisfaction, absence from work and turnover among nurses. Journal of Nursing and Midwifery Sciences, 1:12-18.

6. Gorman E, Yu S, Alamgir H (2010): When healthcare workers get sick: exploring sickness absenteeism in British Columbia, Canada. Work Reading Mass, 35:117-123.

7. Duclay E, Hardouin JB, Sebille V, Anthoine E, Moret L (2015): Exploring the impact of staff absenteeism on patient satisfaction using routine databases in a university hospital. Journal of nursing management, 23:833-841.

8. Moret L, Anthoine E, Paille C, Tricaud-Vialle S, Gerbaud L, Giraud-Roufast , et al. (2012): Relationship between inpatient satisfaction and nurse absenteeism: an exploratory study using WHO-PATH performance indicators in France. BMC Res Notes, $5: 83$.

9. Nyathi M, Jooste K (2008): Working conditions that contribute to absenteeism among nurses in a provincial hospital in the Limpopo Province. Curationis, 31:28-37.
10. Unruh L, Joseph L, Strickland M (2007): Nurse absenteeism and workload: negative effect on restraint use, incident reports and mortality. Journal of advanced nursing, 60:673-681.

11. Baydoun M, Dumit N, Daouk-Oyry L (2016): What do nurse managers say about nurses' sickness absenteeism? A new perspective. Journal of nursing management, 24:97-104.

12. Mudaly P, Nkosi ZZ (2015): Factors influencing nurse absenteeism in a general hospital in Durban, South Africa. Journal of nursing management, 23:623631.

13. Davey MM, Cummings G, Newburn-Cook CV, Lo EA (2009): Predictors of nurse absenteeism in hospitals: a systematic review. Journal of nursing management, 17:312-330.

14. Becker SG, Oliveira ML (2008): Study on the absenteeism of nursing professionals in a psychiatric center in Manaus, Brazil. Revista latino-americana de enfermagem, 16:109-114.

15. Al-Ahmadi H (2009): Factors affecting performance of hospital nurses in Riyadh Region, Saudi Arabia. International journal of health care quality assurance, 22:40-54.

16. Alpern R, Canavan ME, Thompson JT, McNatt Z, Tatek D, Lindfield T, et al. (2013): Development of a brief instrument for assessing healthcare employee satisfaction in a low-income setting. PLoS One, 